\title{
Upaya Peningkatan Pendapatan Nelayan Melalui Lembaga Nelayan
}

\author{
Moh. Ali Akbar ${ }^{*}$, Henny Oktavianti ${ }^{2}$ \\ ${ }^{1,2}$ Fakultas Ekonomi Dan Bisnis Universitas Trunojoyo Madura
}

\section{Informasi Artikel \\ Sejarah artikel: \\ Diterima Desember 2018 \\ Disetujui Oktober 2019 \\ Dipublikasikan Oktober 2019}

\section{Keywords: \\ Institutional, \\ Fishermen}

Income

\begin{abstract}
The purpose of this study is to determine the role and efforts for the economic prosperity of Masalembu fishermen. The research method in this study uses a qualitative method by describing the phenomena that occur in society. Data collection techniques that researchers use are with field studies namely interviews, observation, and documentation. Community empowerment is one important factor in overcoming the welfare of the Masalembu fishing community. The results showed that welfare can be achieved by increasing the income of fishermen, such as using it because of a fishing institution as one of the driving forces of the economy. The welfare of Masalembu fishermen is low because the role and contribution of the Masalembu fishing institute are still low.
\end{abstract}




\section{PENDAHULUAN}

Kelautan dan perikanan di wilayah Madura merupakan sumber daya yang melimpah dan selalu berkorelasi dengan nelayan. Masyarakat nelayan adalah masyarakat yang tinggal di dekat pantai atau pesisir (Saidi, 2014).

Sumenep merupakan salah satu kabupaten penyumbang produksi perikanan tangkap terbesar di Madura. Hal ini karena memiliki potensi sumberdaya pesisir dan lautan paling dominan (Efendy, 2011). Misalnya tahun 2016 sebesar $46.672,80$ ton. Penyumbang terbesar ialah Kecamatan Dungkek, Kecamatan Ambunten, Kecamatan Sapeken, dan Kecamatan Masalembu sebesar 3.146 ton. Belakangan ini seringkali masyarakat Masalembu mendapati nelayan yang dari luar daerah, merusak rumah ikan (Rumpon) yang telah dibuat oleh para nelayan Masalembu. Salah satunya dengan menggunakan cantrang atau pukat harimau. Rumah-rumah ikan yang dibuat oleh nelayan Masalembu modalnya sangat besar, terdiri dari bambu sejumlah 10 sampai 15 bambu dan harga dari per-1 bambu biasanya dihargai Rp. 15.000 sampai dengan Rp. 30.000 kemudian daun kelapa (Lerep) sebanyak 100 sampai dengan 200 buah yang dihargai sejumlah Rp. 2000 sampai dengan Rp. 3000 serta tali besar dan pengapung seharga Rp. 200.000 dan hal tersebut terus berulang-ulang tiap bulan.

Mereka (nelayan luar daerah) yang menggunakan alat tangkap modern menangkap ikan tidak memperhatikan lingkungan dan semena-mena pada perairan dan rumah ikan yang telah dibuat oleh nelayan lokal. Seringkali nelayan luar daerah yang menggunakan alat tangkap modern memutus dan merusak investasi dari nelayan lokal, juga memanen ikannya dengan pukat harimau dan alat tangkap berat lainnya akibatnya mata pencaharian nelayan lokal yang semula hanya bergantung pada investasi tersebut menjadi rusak dan tidak mempunyai harapan dalam menangkap ikan. Alat tangkap tidak dapat digunakan terus menerus, hal ini berkaitan dengan perubahan musim ikan yang terjadi pada wilayah perairan tersebut (Firdaus, 2013). Terjadinya perubahan musim ikan tentu saja merubah alat tangkap yang akan digunakan oleh nelayan. Kondisi tersebut tentu saja berdampak kepada pendapatan real masyarakat nelayan lokal.

Masyarakat yang berprofesi nelayan di Masalembu sepakat ketika mendapati nelayan luar daerah yang ditemui sedang memanen ikannya dan memutus mata pencaharian mereka, mereka menangkapnya ditengah lautan kemudian digiring kedaratan. Mereka yang semula sudah diperingati untuk tidak merusak rumah ikan (Rumpon) mereka tetap saja kembali datang dan merusaknya. Adanya peran tersebut kemudian nelayan luar daerah, menyebut nelayan lokal sebagai bajak laut. Proses peranan nelayan lokal tadi dalam melindungi mata pencaharian nya dan dalam usaha peningkatan kesejahteraan nya (pendapatan) disitu terdapat kontradiksi dari peranan tersebut yaitu nelayan lokal tetap saja tidak sejahtera.

Masalembu telah terdapat lembaga pemberdayaan masyarakat nelayan sebanyak 9 lembaga nelayan. Mengingat dalam pembentukan sebuah lembaga terdapat aturan main, maka lembaga yang telah dibentuk tersebut pasti memiliki tugas pokok dan fungsi serta agenda tersendiri dalam meningkatkan kesejahteraan penduduk nelayan di Masalembu. Setelah adanya aksi proteksi dari masyarakat nelayan Masalembu tentunya pasti akan memiliki impact tersendiri ketika proteksi yang dilakukan adalah untuk menjaga sustainable lumbung penghasilannya, misalnya setelah adanya proteksi tersebut, maka jumlah ikan akan tetap banyak, sehingga bukan tidak mungkin bahwa masyarakat nelayan Masalembu perekonomiannya menjadi sejahtera. Untuk alasan itulah peneliti tertarik untuk meneliti lebih lanjut 
tentang topik diatas karena mengaca kepada pendapat (Hadi, 2014) yang mengatakan kekuatan kelembagaan lokal seperti kelembagaan nelayan ini mempunyai peran penting dalam mendorong aktivitas ekonomi masyarakatnya.

\section{METODE PENELITIAN}

Penelitian ini merupakan penelitian yang memaparkan tentang fenomena yang terjadi dilapangan dengan pendekatan kualitatif. Metode kualitatif memberikan sumbangan terhadap perubahan teori baru melalui pemahaman proses perilaku dan pengalaman individu (Susila, 2015). Tujuannya ialah untuk mengetahui upayaupaya peningkatan pendapatan masyarakat nelayan Masalembu melalui lembaga pemberdayaan masyarakat nelayan di Masalembu Kabupaten Sumenep.

Teknik analisis data yang digunakan dalam penelitian ini adalah kualitatif secara induktif. Tujuan dari metode ini tidak lain adalah untuk mendeskripsikan suatu fenomena yang terjadi yang berupa gambaran-gambaran, lukisan secara sistimatis faktual dan akurat mengenai sifatsifat, serta fakta-fakta yang sedang diselidiki. Sesuai dengan definisi yang digagas oleh Whitney, bahwasanya metode kualitatif deskriptif ini adalah mencari suatu kebenaran atau fakta melalui interpretasi yang tepat. Selanjutnya untuk mengecek kebenaran suatu data digunakan teknik pengecekan dengan teknik triangulasi sumber, dimana prosesnya ialah membandingkan dengan data yang diperoleh dari sumber lain, pada berbagai tahap penelitian dilapangan, serta pada saat yang berlainan dan dengan menggunakan metode yang berlainan (Moeleong, 2014).

\section{HASIL DAN PEMBAHASAN \\ Menjaga Modal Sosial antar Nelayan}

Modal sosial adalah sumberdaya yang dimiliki oleh masyarakat dalam bentuk norma-norma atau nilai-nilai yang memfasilitasi dan membangun kerja sama melalui jaringan interaksi dan komunikasi yang harmonis dan kondusif. Modal sosial berdasarkan karakter sosial budaya masyarakat terdiri dari dua jenis, yaitu modal sosial terikat dan modal sosial yang menjembatani (Pontoh, 2010). Perbedaan keduanya dapat ditemui melalui penggambaran karakter-karakter sosial budaya di masyarakat yang terkait dengan karakter setiap modal sosial.

Sedangkan dalam arti institusionalisasinya ialah kehidupan bersama, peran, wewenang, tanggung jawab, sistem penghargaan dan keterikatan lainnya yang menghasilkan tindakan kolektif. Selain itu bentuk modal sosial sebagai hubungan

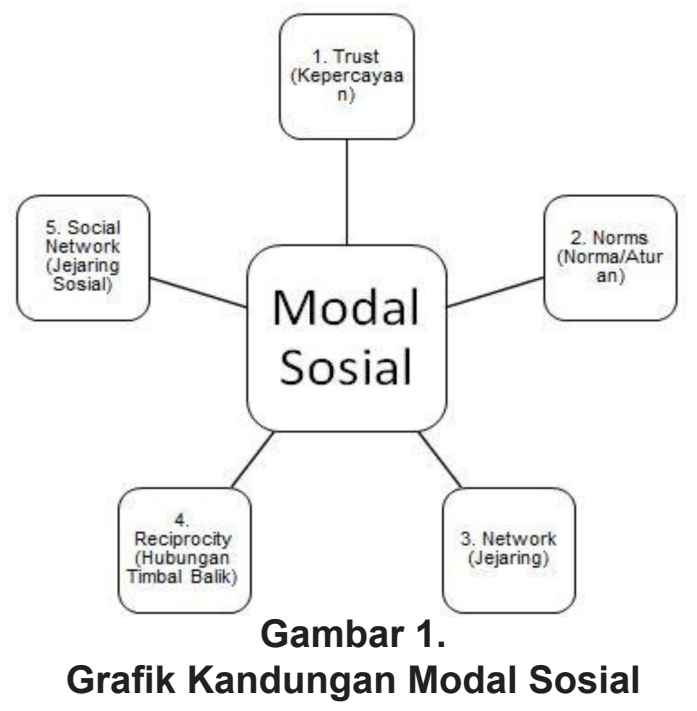


yang tercipta dari norma sosial yang menjadi perekat sosial, yaitu terciptanya sebuah kesatuan dalam anggota kelompok secara bersama-sama. (Yustika, 2008). Sesuai dengan ide utama yang digagas oleh Putnam bahwasanya modal sosial ialah terdiri dari 5 yang tercakup pada gambar 1.

Berdasarkan pada ide utama gagasan Robert D. Putnam, selanjutnya peran Lembaga Permberdayaan Masyarakat Nelayan (LPMN) Masalembu diuraikan kembali sesuai dengan unsur modal sosial diatas. Antara lain meliputi:

A. Mengadakan Petik Laut (Norma/ Aturan)

\section{B. Perlindungan Kawasan Tangkap (So- cial Networking)}

Peran ini dilakukan tujuannya ialah agar nelayan luar daerah (nelayan modern) tidak merusak sumber daya yang dibangun tersebut. Biasanya langkah masyarakat nelayan dalam melindungi kawasan tangkap ikan ini ialah setiap nelayan luar daerah (nelayan modern) didapati sedang bekerja dirumah ikan (buatan) milik para nelayan pribumi. Alasan para nelayan pribumi melakukan tindakan yang demikian ialah karena nelayan modern (nelayan luar daerah) sangat merugikan ketika bekerja didaerah penangkapan masyarakat pribumi.

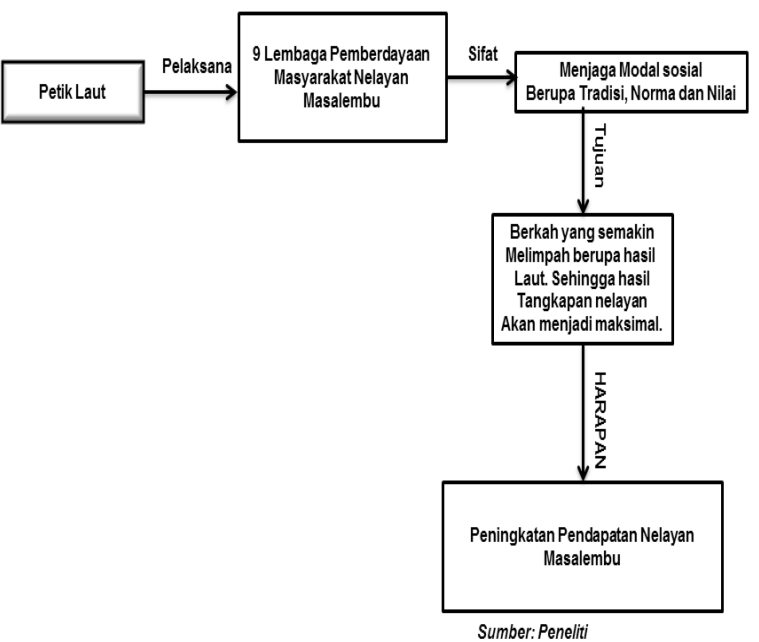

Gambar 2.

Petik Laut dan Hubungannya dengan Peningkatan Pendapatan Nelayan

Peran lembaga nelayan yang pertama dalam meningkatkan pendapatan nelayan ini ialah menjaga modal sosial melalui tradisi, norma/aturan (Norm). Tujuan dari pengadaan acara "Petik Laut" atau selamatan pantai ini ialah saat atau setelah mengadakan acara ini, diharapkan agar berkah yang didapatkan semakin melimpah dari hasil lautnya. Juga nantinya para nelayan saat sedang bekerja akan mendapatkan hasil tangkap yang maksimal.
Sehingga sebagian nelayan mengatakan bahwasanya pendapatannya mulai menurun karena adanya nelayan modern tersebut. Kronologinya ialah saat nelayan luar daerah (nelayan modern) melakukan hal yang demikian maka secara tidak langsung nelayan pribumi akan membuat ulang atau membangun rumah ikan tersebut dari awal. Mekanisme perlindungan tersebut ialah informatif melalui trust (kepercayaan) antar sesama nelayan melalui peran tersebut para nelayan berharap agar pendapatannya stabil dan bahkan meningkat. 


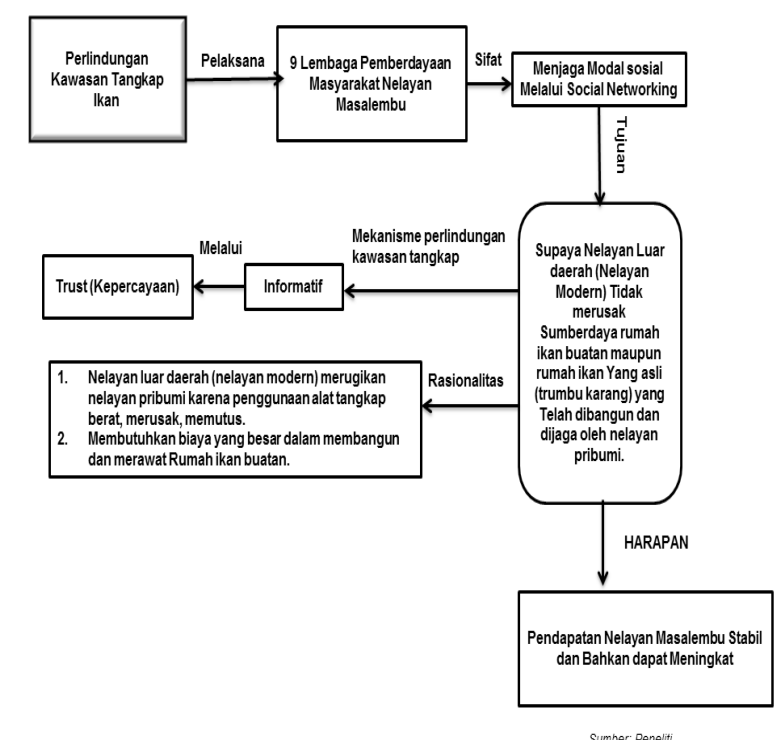

Gambar 3.

Perlindungan Kawasan Tangkap Ikan dan Hubungannya dengan Peningkatan Pendapatan Nelayan

Upaya Penjaringan Bantuan dari Pemerintah Kepada Nelayan

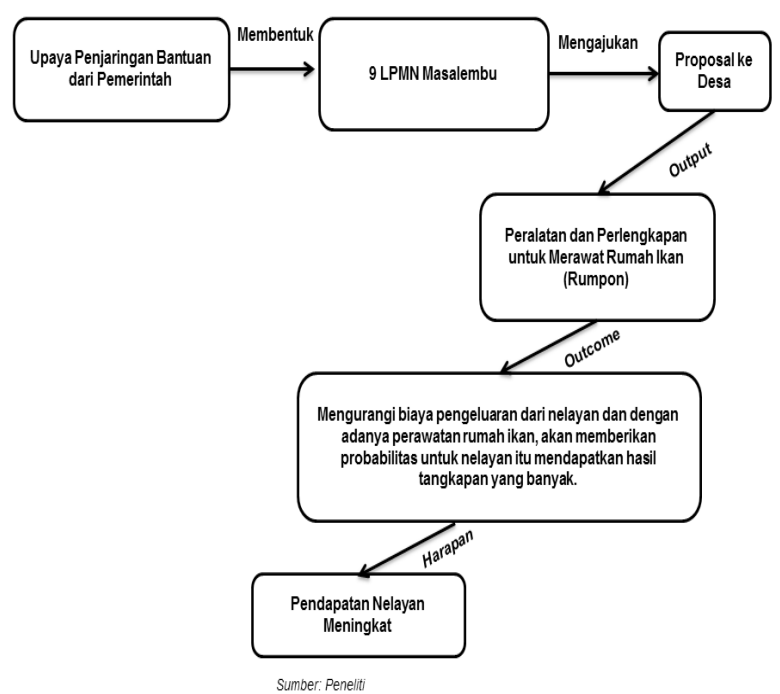

Gambar 4.

Upaya Penjaringan Bantuan pada Nelayan dan Hubungannya dengan Peningkatan Pendapatan Nelayan

Adapun peran ini dilakukan oleh lembaga nelayan tujuannya tidak lain ialah untuk membantu para nelayan agar biaya yang dikeluarkan untuk keperluan nelayan menjadi berkurang. Sistem ini sama halnya dengan pemberian subsidi dari pemerintah. Dengan asumsi apabila pengeluaran berkurang maka selanjutnya penerimaan atau pendapatannya diharapkan dapat meningkat. 


\section{Perlindungan Rumah Ikan}

Peran yang selanjutnya ini merupakan regulasi yang telah dibuat oleh lembaga nelayan dengan tujuan agar para nelayan juga tidak semena-mena dalam mengeksploitasi sumberdaya ikan dirumah ikan milik nelayan lain. Karena asumsinya ialah jika nelayan yang bukan pemilik tidak mengeksploitasi sumber daya ikan di rumah ikan nelayan lain maka sumberdaya tersebut akan tetap. Sehingga nelayan pemilik dapat memanfaatkan sumberdaya ikan tersebut secara maksimal dan harapannya kemudian ialah terjadinya kenaikan pendapatan. Mekanisme perlindungan rumah ikan ini ialah informatif dengan saling percaya (trust) antar sesama nelayan. Berikut ialah bagan dari deskripsi diatas: terhadap fasilitas publik. Sehingga menyebabkan munculnya free rider dan hal itulah kemudian menjadikan peran tersebut tidak efisien.

\section{KESIMPULAN}

Sampai dengan saat ini diketahui bahwa peran lembaga pemberdayaan masyarakat nelayan di Masalembu telah terdapat tiga peran diantaranya ialah:

1. Menjaga modal sosial

a. Mengadakan petik laut (norm/aturan).

b. Menjaga kawasan tangkap ikan dari nelayan luar daerah yang modern (social networking).

2. Upaya penjaringan bantuan dari pemerintah kepada masyarakat nelayan.

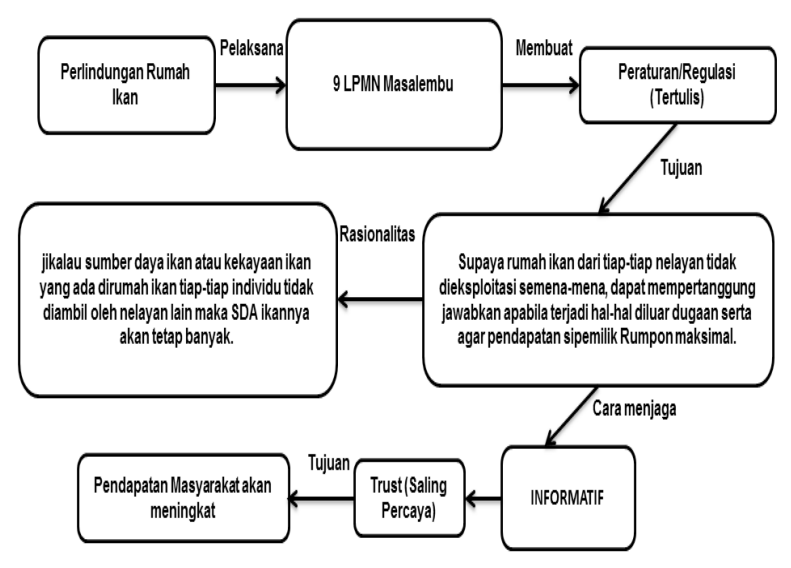

\section{Sumber. Penelifi \\ Gambar 5. \\ Perlindungan Rumah Ikan dan Hubungannya dengan Peningkatan Pendapatan Nelayan}

Dari kesemua peran lembaga pemberdayaan masyarakat nelayan diatas, sampai dengan saat ini belum dapat membuat pendapatan nelayan Masalembu meningkat. Alasannya ialah karena kesemuanya dari peran tersebut ialah berupa harapan. Selain itu ketidak mampuan lembaga dalam mewujudkan terjadinya kenaikan pendapatan juga disebabkan oleh regulasi yang melarang konsumsi
3. Perlindungan rumah ikan.

Namun dari kesemua peran diatas, sampai dengan saat ini belum dapat membuat pendapatan nelayan Masalembu meningkat. Alasannya karena kesemuanya dari peran tersebut ialah berupa harapan. Selain itu ketidakmampuan lembaga dalam mewujudkan terjadinya kenaikan pendapatan juga disebabkan oleh regulasi yang melarang konsumsi terhadap fasili- 
tas publik. Sehingga menyebabkan munculnya free rider dan hal itulah kemudian menjadikan peran tersebut tidak efisien.

\section{DAFTAR PUSTAKA}

Efendy, A. F. S. Dan M. (2011). Studi Sumberdaya Potensial Di Wilayah Pesisir Dan Lautan Kabupaten Sumenep. Jurnal Ilmiah Perikanan Dan Kelautan, 3(2), 235-239.

Firdaus, M. (2013). Pola Penggunaan Alat Tangkap Ikan Di Desa Ketapang Barat, Kabupaten Sampang, Jawa Timur. Buletin Riset Sosek Kelautan Dan Perikanan, 8(1), 9-14.

Hadi, S. (2014). Peran Kelembagaan Lokal Terhadap Aktivitas Ekonomi Masyarakat Pesisir Di Kabupaten Jember. Agribios, 11(1), 28-42.

Moeleong, L. J. (2014). Metodologi Penelitian Kualitatif. Bandung: Pt Remaja Rosdakarya.

Pontoh, O. (2010). Identifikasi Dan Analisis Modal Sosial Dalam Rangka Pemberdayaan Masyarakat Nelayan Desa Gangga Dua Kabupaten Minahasa Utara. Jurnal Perikanan Dan Kelautan Tropis, 6(3), 125-133.

Saidi, M. (2014). Model Pemberdayaan Ekonomi Masyarakat Nelayan (Studi Sistem Bagi Hasil Perikanan Di Wilayah Madura). Jurnal IImu Ekonomi \& Manajemen, 10(1), 39-48.

Susila, I. (2015). Pendekatan Kualitatif Untuk Riset Pemasaran Dan Pengukuran Kinerja Bisnis. Benefit Jurnal Manajemen Dan Bisnis, 19(1), 12-23.

Yustika, A. E. (2008). Ekonomi Kelembagaan Definisi Teori Dan Strategi,. Malang: Banyumedia Publishing. 